\title{
ALIMENTAÇÃO DE Spodoptera frugiperda EM MILHOS Bt EXPRESSANDO AS PROTEÍNAS Cry1F E Cry1A105 + Cry2Ab2 + Cry1F EM LABORATÓRIO
}

\author{
VINHA, Fernando Belezini ${ }^{1}$ \\ RODRIGUES, Luis Rodolfo ${ }^{1}$ \\ PINTO, Alexandre de Sene ${ }^{1}$
}

\begin{abstract}
RESUMO: Os milhos transgênicos que expressam as proteínas Cry1F e Cry1A105 + Cry2Ab2 + Cry1F, são utilizados para o controle de lagartas de Spodoptera frugiperda em milho. Esse trabalho teve por objetivo determinar a ação das proteínas referidas no $3^{\circ}$ e $5^{\circ}$ ínstar de $S$. frugiperda em laboratório. Foi avaliado o $3^{\circ}$ ínstar larval alimentado com folhas do milho transgênico (Cry1A105 + Cry2Ab2 + Cry1F) e o $5^{\circ}$ ínstar larval alimentado com folhas do milho transgênico (Cry1F). Para o tratamento com Cry1A105 + Cry2Ab2 + Cry1F foram utilizadas 150 lagartas criadas em dieta artificial, individualizadas, enquanto para Cry1F foram utilizadas 100 lagartas. Após três dias de alimentação em folhas de milho transgênico (Cry1A105 + Cry2Ab2 + Cry1F) 92\% das lagartas morreram e as lagartas sobreviventes morreram em um dia após mudarem para o $4^{\circ}$ ínstar. A duração média do $3^{\circ}$ ínstar foi significativamente diminuído $(2,45 \pm 0,05)$ no milho transgênico em relação ao convencional $(3,97 \pm 0,04$ dias $)$. O milho transgênico (Cry1A105 + Cry2Ab2 + Cry1F) é eficaz no controle de lagartas de $3^{\circ}$ ínstar de $S$. frugiperda. Para o milho transgênico (Cry1F), verificou-se que as lagartas mais desenvolvidas não são eficazmente controladas pela proteína Cry1F em laboratório, mas as pupas formadas não dão origem a adultos. Dessa forma, conclui-se que o milho transgênico (Cry1F) é eficiente no controle de lagartas de $5^{\circ}$ ínstar de S. frugiperda, causando mortalidade e afetando o desenvolvimento das pupas formadas.
\end{abstract}

Palavras-chave: Transgênicos, Toxinas, Lagarta-do-cartucho.

\section{FEEDING OF Spodoptera frugiperda WITH Bt MAIZE EXPRESSING THE PROTEINS Cry1F AND Cry1A105 + Cry2Ab2 + Cry1F UNDER LABORATORY}

SUMMARY: The transgenic Bt maize that express the proteins Cry1F and Cry1A105 + Cry2Ab2 + Cry1F, are used for the control of Spodoptera frugiperda caterpillars. This work aimed to determine the action of proteins cited on $3^{\text {rd }}$ and $5^{\text {th }}$ instars of $S$. frugiperda under laboratory. The $3^{\text {rd }}$ larval instar fed with transgenic Bt maize leaves (Cry1A105 $+\mathrm{Cry} 2 \mathrm{Ab} 2+\mathrm{Cry} 1 \mathrm{~F})$ and the $5^{\text {th }}$ larval instar fed with transgenic Bt maize leaves (Cry1F) were evaluated. For treatment with Cry1A105 + Cry2Ab2 + Cry1F, 150 caterpillars reared on an artificial diet were used, individualized, and for Cry1F were used 100 caterpillars. After three days of feeding on transgenic maize leaves (Cry1A105 + Cry $2 \mathrm{Ab} 2+\mathrm{Cry} 1 \mathrm{~F}) 92 \%$ of the caterpillars died and the surviving caterpillars died within a day after moving to the $4^{\text {th }}$ instar. The average duration of the $3^{\text {rd }}$ instar was significantly reduced $(2.45 \pm 0.05)$ in transgenic Bt maize compared to Non-Bt maize (3.97 \pm 0.04 days). Transgenic maize (Cry1A105 + Cry2Ab2 + Cry1F) was effective in controlling $3^{\text {rd }}$ instar $S$. frugiperda caterpillars. For transgenic maize (Cry1F), it was found that the most developed caterpillars were not effectively controlled by the Cry1F protein under laboratory, but the pupae formed do not gave rise to adults. Thus, it was concluded that transgenic maize (Cry1F) was efficient in the control of $5^{\text {th }}$ instar $S$. frugiperda caterpillars, causing mortality and affecting the development of formed pupae.

Keywords: Transgenic, Toxins, Fall armyworm.

\section{INTRODUÇÃO}

Como bioinseticida, a bactéria Bacillus thuringiensis (Bt), vem sendo usada há décadas (FEITELSON et al., 1992) e está registrado sem limitação de uso, para o controle de várias espécies-praga de Lepidoptera. Uma das frações ativas produzidas pelo Bt são proteínas acumuladas em forma de cristal no interior das células, denominadas "Cry", que podem constituir mais de $30 \%$ do total de proteínas da célula (HERMSTADT et al., 1986).

\footnotetext{
${ }^{1}$ Moura Lacerda University, Agronomy Department, Ribeirão Preto,SP.
} 
Waquil et al. (2004) comentam que até 2004 haviam duas diferentes toxinas do $B$. thuringiensis disponíveis em milho transgênico para a lagarta-do-cartucho, Spodoptera frugiperda, do milho: Cry1A (b) e Cry1F. A CL50 foi suficiente para inibir o acúmulo de biomassa das larvas em $91,61 \%$ e $89,81 \%$ para Cry1 Ab e Cry1F, respectivamente. As larvas que sobreviveram por dez dias nas dietas tratadas com o Cry1A (b) foram transferidas para dieta não tratada e observadas até a emergência dos adultos. Das larvas sobreviventes, 62,8\% recuperaram seu desenvolvimento, acumulando a biomassa de uma pupa normal. Portanto, a atividade biológica da toxina do Bt vai além da simples toxicidade, incluindo uma significativa inibição de alimentação.

Buntin (2008) avaliou a eficiência de dois híbridos transgênicos de milho expressando as endotoxinas inseticidas Cry1 Ab (evento MON810) ou Cry1F (evento TC1507) e verificou que ambas foram eficientes no controle de S. frugiperda, mas MON810 não apresentou a mesma performance em altas infestações do inseto.

O milho transgênico, expressando a toxina Cry1A(b), tem apresentado níveis razoáveis de resistência (WILLIAMS et al., 1998). Adicionando-se palha de milho transgênico, liofilizada, em dieta artificial, notou-se redução de $40 \%$ na sobrevivência e de $94 \%$ na biomassa das larvas $S$. frugiperda (WILLIAMS et al., 1998).

São escassos os trabalhos que avaliam a eficiência de milho transgênico em laboratório e, por isso, este trabalho teve por objetivo avaliar a eficiência dos milhos transgênicos expressando as proteínas Cry1F e Cry1A105 + Cry2Ab2 + Cry1F no controle de lagartas de S. frugiperda e o efeito nas pupas formadas em laboratório.

\section{MATERIAL E MÉTODO}

\section{Local e semeadura}

Os experimentos foram conduzidos no laboratório de entomologia da Instituição Universitária Moura Lacerda, em Ribeirão Preto, SP.

A semeadura dos milhos expressando as proteínas Cry1F e Cry1A105 + Cry2Ab2 + Cry1F foram realizadas em substrato contendo terra vegetal,areia e vermiculita contido em copos plásticos de $500 \mathrm{~mL}$, mantidos em casa-de-vegetação com irrigação. Foram realizadas semeaduras semanalmente, dos milhos transgênicos e suas isolinhas, para a manutenção das plantas durante o ensaio. Quando as plantas chegavam a 15-20 dias após a semeadura, eram utilizadas nos experimentos. 


\section{Criação das lagartas}

As lagartas de $S$. frugiperda utilizadas foram criadas no Laboratório de Biologia de Insetos do Departamento de Entomologia e Acarologia da Esalq/USP, Piracicaba, SP, em dieta artificial à base de feijão, levedura de cerveja, germe-de-trigo, farelo de soja e caseína por muitas gerações.

\section{Experimento com as proteínas Cry1A105 + Cry2Ab2 + Cry1F}

Foi conduzido um ensaio para avaliar o efeito do milho transgênico no $3^{\circ}$ ínstar de $S$. frugiperda. Foram comparadas lagartas se alimentando em folhas de milho transgênico expressando as proteínas Cry1A105 + Cry2Ab2 + Cry1F e sua isolinha não transgênica.

Pedaços das folhas de $5 \mathrm{~cm}$ de comprimento foram cortados, higienizados em solução de água destilada e hipoclorito de sódio a $0,2 \%$ por 2 minutos e secos em papel-filtro. Cada pedaço foi colocado sobre papel-filtro umedecido no fundo de uma placa acrílica de $2 \mathrm{~cm}$ de altura e 8 cm de diâmetro, desinfetadas com álcool $96 \%$. Sobre a folha foi colocada uma lagarta recém transformada no ínstar a ser estudado. Todo o conjunto foi mantido em uma câmara climatizada mantida a $27 \pm 1^{\circ} \mathrm{C}, 70 \pm 10 \%$ de umidade relativa do ar e $14 \mathrm{~h}$ de fotofase. Foram preparadas 150 placas dessas descritas (repetições) para o milho transgênico e sua isolinha.

Diariamente, as placas foram vistoriadas, anotando-se, em grupos de 10, o número de lagartas mortas ou que mudavam de ínstar, trocando o pedaço de folha e umedecendo o papelfiltro. As avaliações foram realizadas até que a lagarta morresse ou trocasse de ínstar.

\section{Experimento com a proteína Cry1F}

Foram conduzidos dois ensaios, para avaliar o efeito do milho transgênico no $5^{\circ}$ ínstar de S. frugiperda e nas pupas oriundas dessas lagartas. Foram comparadas lagartas se alimentando em folhas de milho transgênico expressando a proteína Cry1F e sua isolinha não transgênica.

Pedaços das folhas de $5 \mathrm{~cm}$ de comprimento foram cortados, higienizados em solução de água destilada e hipoclorito de sódio a $0,2 \%$ por 2 minutos e secos em papel-filtro. Cada pedaço foi colocado sobre papel-filtro umedecido no fundo de uma placa acrílica de $2 \mathrm{~cm}$ de altura e 8 $\mathrm{cm}$ de diâmetro, desinfetadas com álcool $96 \%$. Sobre a folha foi colocada uma lagarta recém transformada no ínstar a ser estudado. Todo o conjunto foi mantido em uma câmara climatizada mantida a $27 \pm 1^{\circ} \mathrm{C}, 70 \pm 10 \%$ de umidade relativa do ar e $14 \mathrm{~h}$ de fotofase. Para cada ínstar, foram preparadas 150 placas dessas descritas (repetições) para o milho transgênico e sua isolinha.

Diariamente, as placas eram vistoriadas, anotando-se, em grupos de 10, o número de lagartas mortas ou que pupavam, trocando o pedaço de folha e umedecendo o papel-filtro. As avaliações foram realizadas até que a lagarta morresse ou trocasse de ínstar. As pupas originadas 
foram mantidas individualmente sobre papel-filtro umedecido e cobertas com copos plásticos de $20 \mathrm{~mL}$, devidamente identificados. Diariamente essas pupas eram vistoriadas para a formação de casais ou anotação da data de morte. Os casais foram mantidos aos pares em gaiolas de PVC de 9 $\mathrm{cm}$ de diâmetro e $10 \mathrm{~cm}$ de altura, revestidas com papel sulfite umedecido e tampadas com placa de Petri de vidro. Como as pupas oriundas de lagartas alimentadas com o milho transgênico Bt não deram origem a adultos, a oviposição não foi avaliada, assim como a longevidade dos adultos.

\section{Análise estatística}

Foram calculadas as porcentagens médias de mortalidade diária e mortalidade acumulada, também foi calculada a duração média do ínstar. Todos os dados obtidos foram submetidos à análise de variância pelo teste $F$ e as médias comparadas pelo teste $t$ a $1 \%$. Todos os cálculos estatísticos foram realizados pelo programa Statistica for Windows (Statsoft, 1996).

\section{RESULTADO E DISCUSSÃO}

\section{Proteínas Cry1A105 + Cry2Ab2 + Cry1F}

A porcentagem média de mortalidade acumulada foi significativamente superior no tratamento onde as lagartas de $3^{\circ}$ ínstar foram alimentadas com folhas de milho transgênico $\mathrm{Bt}$ Cry1A105 + Cry2Ab2 + Cry1F, sendo de 51\% após dois dias de alimentação e de $92 \%$ após três dias. A mortalidade no milho convencional foi de apenas $1 \%$ em todas as datas, pois as lagartas atingiram o quarto ínstar (Figura 1).

As lagartas que atingiram o quarto ínstar no tratamento transgênico morreram após um dia, chegando a $100 \%$ a mortalidade. 
Figura 1. Mortalidade média diária acumulada (\%) de lagartas de $3^{\circ}$ ínstar de S. frugiperda alimentandose de folhas de milho transgênico expressando as proteínas Cry1A105 + Cry2Ab2 + Cry1F e sua isolinha (convencional) em laboratório $\left(27 \pm 1^{\circ} \mathrm{C}, 70 \pm 10 \%\right.$ de U.R. e $14 \mathrm{~h}$ de fotofase).

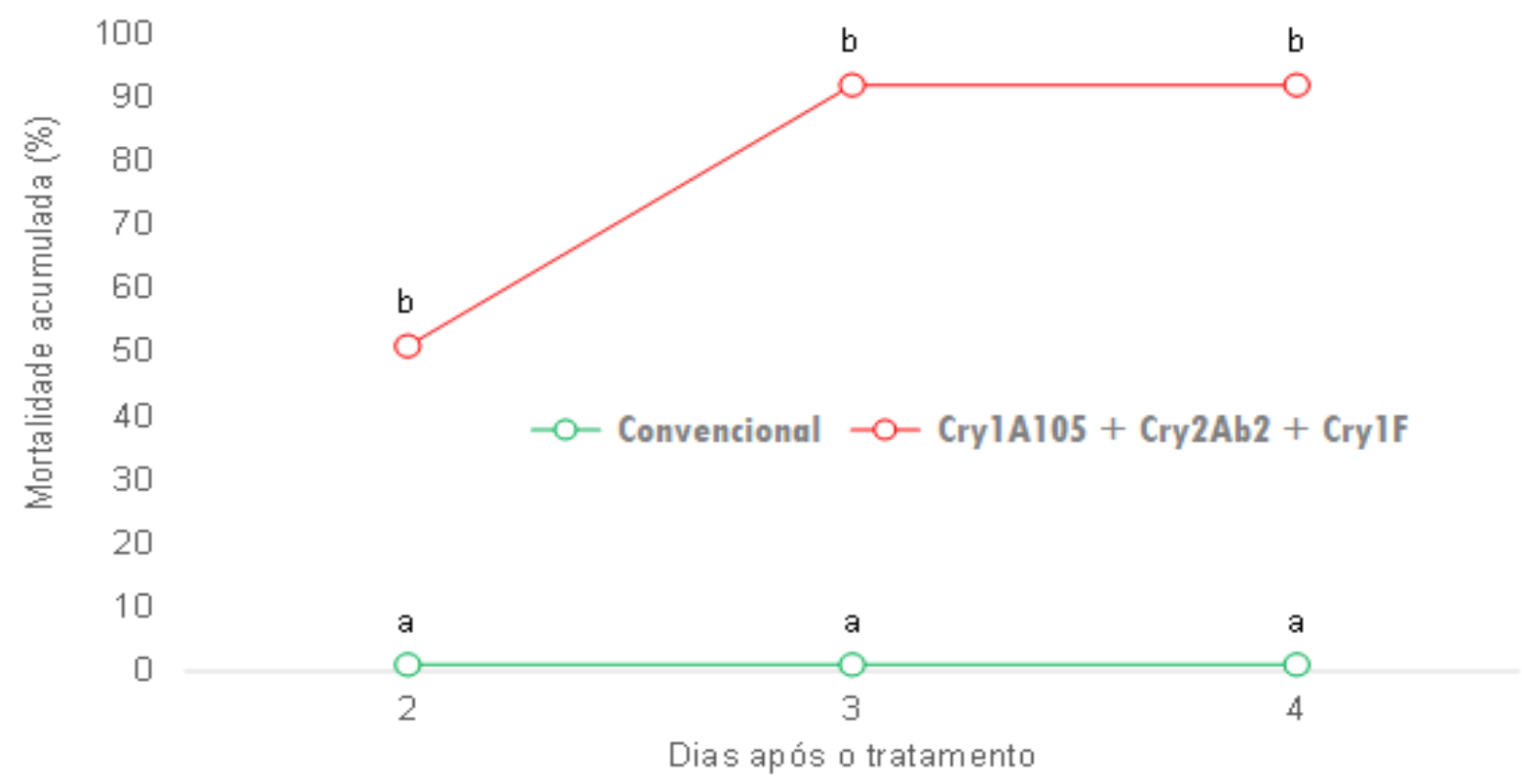

Pontos seguidos pela mesma letra não diferem entre si pelo teste $t(\alpha \leq 0,01)$.

A duração média do terceiro ínstar foi significativamente inferior no tratamento transgênico, ficando em 2,45 \pm 0,05 dias, em média, em comparação com a isolinha, que foi de 3,97 \pm 0,04 dias (Figura 2). A alimentação em folhas do milho expressando as proteínas Cry1A105 + Cry2Ab2 + Cry1F acelerou o desenvolvimento dos $8 \%$ de lagartas que atingiram o quarto ínstar. 
Figura 2. Duração média (dias) do $3^{\circ}$ ínstar de $S$. frugiperda alimentando-se de folhas de milho PowerCore ${ }^{\circledR}$ e sua isolinha (convencional) em laboratório $\left(27 \pm 1^{\circ} \mathrm{C}, 70 \pm 10 \%\right.$ de U.R. e $14 \mathrm{~h}$ de fotofase).

5

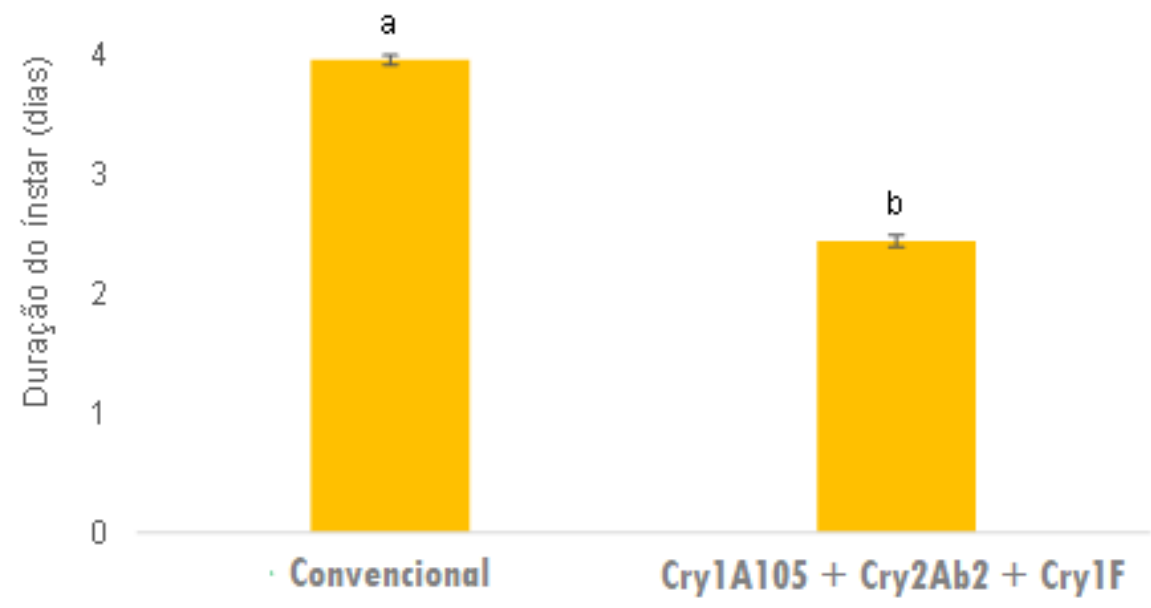

Colunas seguidas pela mesma letra não diferem entre si pelo teste $t(\alpha \leq 0,01)$.

\section{Proteína Cry1F}

A mortalidade média acumulada de lagartas de $5^{\circ}$ ínstar alimentadas de folhas da isolinha não transgênica chegou a $20 \%$ até o $16^{\circ}$ dia de desenvolvimento e o restante pupou. Por outro lado, aquelas alimentadas em folhas de milho expressando a proteina Cry1F atingiram mortalidade de $88 \%$ até o $16^{\circ}$ dia. Houve diferenças significativas entre os tratamentos a partir do $3^{\text {o }}$ dia de desenvolvimento das lagartas (Figura 3).

As pupas oriundas de lagartas alimentadas com folhas de milho transgênico Bt não deram origem a adultos, pois estavam defeituosas ou morreram e, portanto, não foram incluídos os parâmetros biológicos de adultos oriundos de lagartas alimentadas com milho convencional. Entretanto, 56\% das lagartas do milho não transgênico passaram a fase de pupa e deram origem a adultos, sendo que $24 \%$ não passaram a essa fase. 
Figura 3. A mortalidade média acumulada de lagartas de $5^{\circ}$ ínstar alimentadas de folhas da isolinha não transgênica chegou a $20 \%$ até o $16^{\circ}$ dia de desenvolvimento e o restante pupou. Por outro lado, aquelas alimentadas em folhas de milho expressando a proteína Cry $1 \mathrm{~F}$ atingiram mortalidade de $88 \%$ até o $16^{\circ}$ dia.

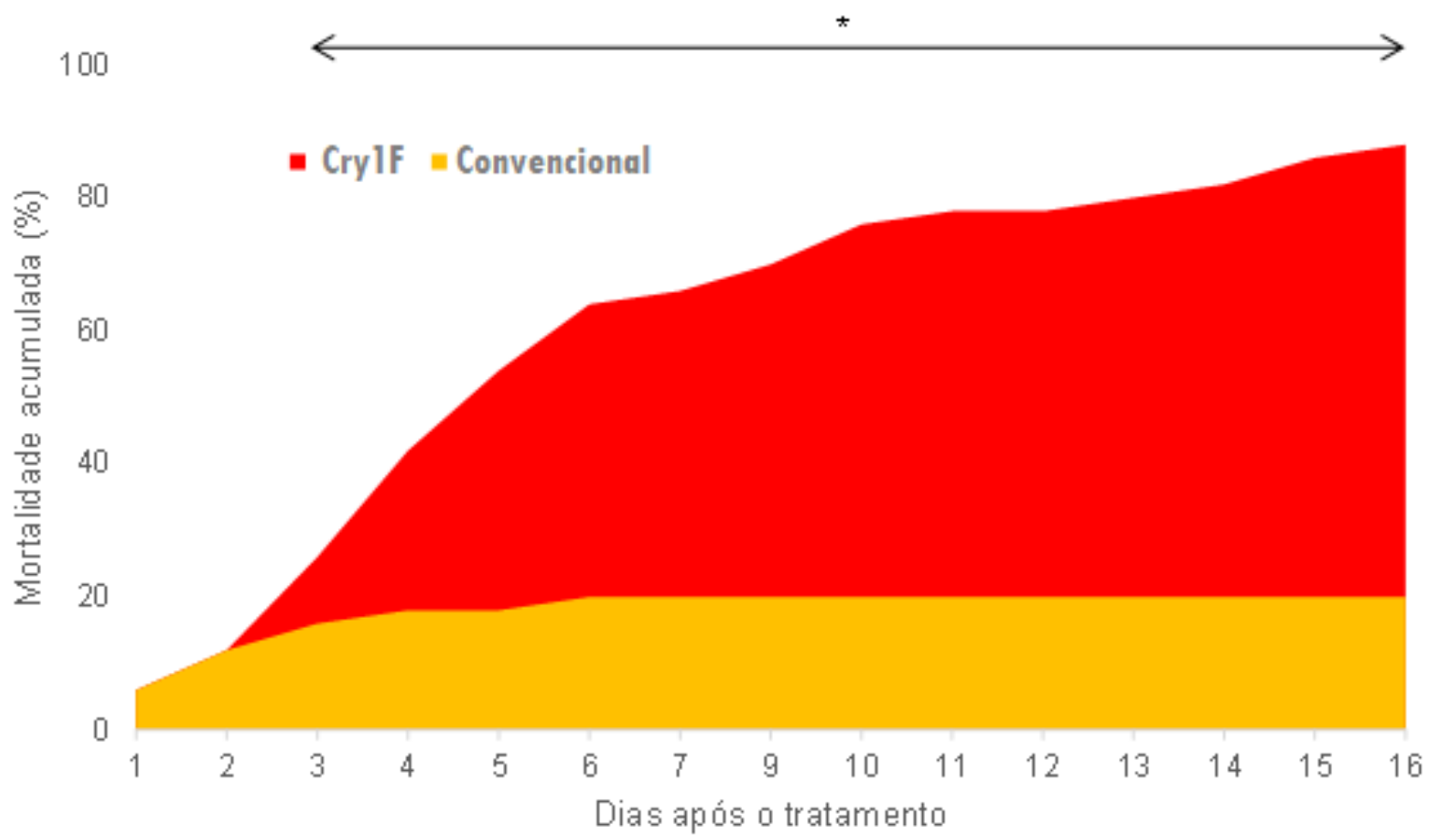

Houve diferenças significativas entre os tratamentos a partir do $3^{\circ}$ dia de desenvolvimento das lagartas.

Blundi (2011) verificou que o milho expressando a proteína Cry1F controla eficientemente lagartas de $2^{\circ}$ e $3^{\circ}$ ínstares de $S$. frugiperda, mas no atual estudo as lagartas de $5^{\circ}$ ínstar apresentaram baixa mortalidade. Entretanto, as pupas oriundas dessas lagartas não chegaram à fase adulta. Outros resultados semelhantes ao atual estudo foram relatados por Siebert et al. (2008) e Waquil et al. (2002), para transgênicos que expressam a toxina Cry1F, onde apresentaram controle eficiente da lagarta S. frugiperda com essa toxina. A lagartas mais desenvolvidas desse estudo continuaram seu desenvolvimento, mas não avançaram para nova geração.

\section{CONCLUSÃO}

O milho transgênico expressando as proteínas Cry1A105 + Cry2Ab2 + Cry1F é eficiente no controle de lagartas de $3^{\circ}$ ínstar de $S$. frugiperda, e o milho expressando a proteína Cry1F é eficiente no controle de lagartas de $5^{\circ}$ ínstar de S. frugiperda em laboratório.

\section{REFERÊNCIAS}

BLUNDI, D. dos S. Controle de Spodoptera frugiperda (Lepidoptera: Noctuidae) utilizando o milho transgênico Herculex* I em laboratório e campo. 2011. 28f. Monografia (Trabalho de Graduação em Agronomia) - Centro Universitário Moura Lacerda, Ribeirão Preto, 2011. 
BUNTIN, G.D. Corn expressing Crylab or Crylf endotoxin for Fall Armyworm and Corn Earworm (Lepidoptera: Noctuidae) management in field corn for grain production. Florida Entomologist, v.91, n.4, p.523-530, 2008.

FEITELSON, J.S.; PAINE, J.; KIM, L. Bacillus thuringiensis: insects and beyond.

Biotechnology, v.10, p.271-275, 1992.

HERMSTADT, C.; SOARES, G.G.; WILCOX, E.R.; EDWARDS, D.L. New strain of Bacillus thuringiensis with activity against Coleopteran insects. Biotechnology, v.4, p.305-308, 1986.

STATSOFT. Statistica for Windows: computer program manual. Tulsa, OK: StatSoft Inc., 1996.

SIEBERT, S.W. et al. Efficacy of Cry1f insecticidal protein in maize and cotton for control of Fall Armyworm (Lepidoptera: Noctuidae). Florida Entomologist, v.91, n.4, p.555-565, 2008.

WAQUIL, J.M.; VILELLA, F.M.F.; FOSTER, J.E. Resistência de milho (Zea mays L.) transgênico à lagarta-do-cartucho, Spodoptera frugiperda (Smith) (Lepidoptera: Noctuidae). Revista Brasileira de Milho e Sorgo, v.1, p.1-11, 2002.

WAQUIL, J.M.; VILELLA, F.M.F.; SIEGDRIED, B.D.; FOSTER, J.E. Atividade biológica das toxinas do Bt, Cry 1A(b) E Cry 1F em Spodoptera frugiperda (Smith) (Lepidoptera: Noctuidae). Revista Brasileira de Milho e Sorgo, v.3, n.2, p.161-171, 2004.

WILLIAMS, W.P. et al. Factors associated with resistance to fall armyworm (Lepidoptera: Noctuidae), and southwestern corn borer (Lepidoptera: Crambidae) in corn at different vegetative stage. Journal of Economic Entomology, v.91, p.1471-1480, 1998. 